\title{
Revealing Prerequisites and Factors of Transactional Costs Formation in the Activity of Educational Establishments through Process Approach
}

\author{
Vorontsova L.V.a \\ Ismagilova G.N.b \\ Kramin T.V.c \\ Grigoryev R.A.d \\ acd Institute of Economics, Management and Law, Kazan, Russian Federation, 420111 \\ ${ }^{b}$ Kazan Federal University, Institute of Management, Economics and Finance, Kazan, 420008, Russia
}

\section{Doi:10.5901/mjss.2015.v6n1s3p188}

\section{Abstract}

The article is devoted to the study of one of the main types of transactional costs in an educational establishment - the costs of assets and processes management. The work uses the process approach of corporate management. The results will be used as the theoretical basis for building the overall architecture of information system, as well as for revealing and classifying the transactional costs in business processes.

Keywords: transactional costs, institutional environment, educational establishment, information system, organizational-functional structure, process approach.

Educational sphere is traditionally characterized by the high level of transactional costs: the uncertainty of the environment and the high degree of specificity of the used assets. Under globalization and increase of international competition, the issues transactional costs management are brought into the foreground (Dietrich, 2008, p. 1), at the same time the agents theory and transactional costs have never been fully applied for educational sphere (Brewer \& McEwan, 2010, p. 7; Murphy \& Louis, 1999, pp. 378-379).

The results of previous research (см. например McMeekin, 2003, pp. 3-13; Воронцова, Крамин, \& Крамин, 2011; Крамин, 2007a) allowed to structure transactional costs of an educational establishment by the transactions type and to distinguish:

1) Transactional costs of interacting with the consumer of educational services;

2) Transactional costs of corporate management (here we understand corporate management as the activity aimed at achieving the balanced interests of all stockholders in the business);

3) Transactional costs of managing assets and processes.

The article is devoted to the study of one of the main types of transactional costs in an educational establishment the costs of managing assets and processes. The work uses process approach ${ }^{1}$ of corporate management. The research results will be used as the theoretical basis for building of the general architecture of informational system and revealing and classifying the transactional costs by business-processes.

In particular, the work has fulfilled the following tasks:

1. The universal business-processes were defined, which are implemented in the academic work in higher educational establishments.

2. The sequences and structures of business-processes are revealed.

3. The key links and structural subdivisions responsible for the business-processes implementation are revealed.

4. The features of processes in educational sphere are studied.

The overall formalized functional structure, determined by the general mission, objectives and tasks of an establishment, results in the organizational structure of each particular university, which, in turn, is the basis for distributing universal business processes, taking place in every university (Brewer \& McEwan, 2010; Seng \& Churilov, 2003). This is connected with a very important constituent of an informational system, aimed at servicing the educational process management, namely, the distribution of roles and control (Carroll \& Teece, 1998). That is why each group of

\footnotetext{
1 See also reviews of approaches to analyzing educational establishments (Brewer \& McEwan, 2010, p. 6).
} 
business processes, united by the goals achieved by them, was viewed separately.

The key functions are those corresponding to the main objectives of the activity, namely: admission commission, academic work, up-bringing and scientific work. At the same time, implementation of these activities would be impossible (Lunenburg \& Ornstein, 2011), or at least difficult, without other subdivisions, such as managing the materials resources, personnel, legal support, informatization and general development. Out of these activities, legal support is not specific for an educational establishment.

At the same time, the organizational structure of an educational establishment abstracted from non-specific types of activity, represent a compressed hierarchy. Each level is designed to solve one task. However, the tasks within one level are highly differentiated.

The structural subdivisions are necessary and sufficient units for implementation of academic process with due quality according to the Russian legislation.

Many researchers agree that managerial structures at universities, formed in the period of administrative-command management system, do not allow the university to promptly react on the external changes and adapt to the new economic conditions (Грудзинский, 2004). The rigid structure does not let universities implement strategic management in many spheres of activity, hence the necessity to radically change the university organizational structure, which should lead to changing its business-processes. Besides, the university organizational structure is highly hierarchical and belongs to linear-functional type. These characteristics predetermine the high level of transactional costs, connected with the complexity and imperfection of informational streams inherent to such structure. The main ways of reducing transactional costs in this sphere are reducing the number of hierarchical levels and transition from the functional structure to cross-functional teams (Groenewegen, 1996).

Alongside with that, speaking about transforming the university management, many researchers and experts focus on priority development and broadening the economic departments, marketing structures, developing infrastructure for entrepreneurship support (business incubators), and strengthening the leading role of administration. However, the structure of departments and faculties is not altered as a rule, as it is taken for granted. Meanwhile the thesis is undoubted that it is the departments and faculties that should become the managing centers. However, the institutions of power delegation within the organization can significantly reduce transactional costs if properly formed and implemented.

Let us view the business processes of an educational establishment diachronically.

Academic work is the main business process at a university; consequently, it must be in the center of attention of the administration. The correct organization and optimization of academic work increases profit through reducing costs, including transactional costs. Providing the high quality of academic work allows to increase competitiveness of educational services, which has a positive impact on their consumer cost and price. An important feature of the correctly organized business process is its flexibility and ability to react to changes.

The research of academic work organization (Hepner \& Dickson, 2013; Joseph \& George, 2002; Watson \& Schneider, 1999) showed that the general description should be made with functional approach, i.e. the systemic interconnection of such managerial functions as planning, processes organization, control, accounting, analysis, making managerial decisions.

Management in education is based on the classical bureaucracy pattern. The processes are initialized by written instructions. The results, the performance, the activities are carried out basing on formal documentation. That is why the business processes related to documentation are very important.

The main unified forms within the educational process are:

1. Order on admission

2. Group register (attendance of theoretical and practical lessons)

3. Order on transfer

4. Test/examination sheets

5. Course paper sheets

6. Control works sheets

7. Order on expulsion

8. Order on directing to probation period

9. Protocol of State Attesting Committee (decision on qualification assignment)

10. State Diploma

Within academic process organization:

1. Individual load

2. Individual plan of a lecturer

3. Weekly schedules (distribution of lectures and rooms among students groups) 
4. Reports on the work execution (delivered lectures)

5. Protocols of department meetings, faculty meetings, University Council meetings.

This list of documents is necessary and obligatory, which predetermines the necessity not only to automatize their flow, but also to design a system of mutual reconciliation of their content, in order to obtain final information on the results of activities and processes serviced by these documents. Besides, their controlling fucntion implies the necessity to create a mechanism of interaction between subdivisions and structures when carrying out the activities under their responsibility.

Up-bringing in an educational establishment is aimed at forming the student's personality, their civil-legal conscience and developing their talents and capabilities.

The state policy regards up-bringing as an inseparable element of education, touching upon all levels and stages of educational system. That is confirmed by the students' activities carried out at the local, regional and federal levels. Consequently, the managerial process should pay due attention to this aspect of activity.

The issue of actual efficiency of up-bringing at university is very complicated. The main problem here is how to ensure harmony in creating and functioning of the up-bringing system. A university faces the danger of overestimating the value of mass activities. The effect of up-bringing usually shows not immediately, but after some time, probably a long time. The varied students life, the broad spectrum of students' interests, makes it impossible to trace which up-bringing activity or impact resulted in the certain up-bringing effect (positive or negative). The up-bringing work fulfils the following tasks:

1. Forming the modern scientific outlook and the system of basic values of the students:

- Forming and developing of spiritual-moral values.

- Creating conditions for realizing and implementing the essence and significance of civil-patriotic values.

- Forming the system of legal knowledge.

- Forming the system of aesthetic and ethic knowledge and values.

- Forming the tolerant thinking and counteraction to extremism.

- Forming the need to work as the primary need in life, supreme value and main way of achieving success in life.

2. Spiritual-moral up-bringing:

- Forming and developing the system of spiritual-moral knowledge and values.

- Implementation of knowledge connected with the moral norms and professional ethics in educational, productive and social life.

- Forming the reproductive conscience and the idea of a family as the basis for restoration of traditional national moral values.

3. Patriotic up-bringing:

- Increasing the social status of patriotic up-bringing of the youth.

- Implementing the scientifically-grounded organizational policy of patriotic up-bringing.

- Increasing the level of the content, techniques and methods of patriotic up-bringing at university on the basis of actual interaction of the educational subdivisions.

4. Forming the health-preserving environment and healthy way of life:

- Broad propaganda of physical culture, sports, and healthy way of life by carrying out of various competitions.

- Propaganda of the healthy way of life, struggle against smoking, drugs-addiction, bad habits.

5. Forming competitiveness:

- Increasing students' motivation for self-improvement.

- Forming orientation towards success, leadership and carrier behaviour.

- Forming the qualities of a socially active personality.

- Self-presentation skills, skills of argumentation, decision-making, organization of socially and personally valuable activities.

From the viewpoint of managerial system, the university must achieve good results in up-bringing, but academic process enjoys the priority, thus, the up-bringing activity is a necessary but limiting element.

Often the achievements of students' groups in competitions and festivals are viewed as an extra component for the university advertising campaign, giving certain advantages before other educational institutions. The modern normative accounting system and assets admittance principles do not admit such advantages. They are not subject to accounting and normative management.

In the management system up-bringing has no determined, universal business processes and, consequently, 
directly estimated tangible results. At the same time the professional management of up-bringing among students as well as lecturers increases their conscientiousness, loyalty, creative activity, reduces the amount of opportunism. As a result, transactional costs are reduced.

Up-bringing activities can be estimated by the allocated funds and the results. As for estimations of its efficiency, it can be carried out not only at subjective level and by expertise, but also by institutional approach, by reducing transactional costs as a result of the up-bringing activities.

Let us consider the potential of scientific activity of universities in the aspect of transactional costs reduction. Universities specializing in the humanities and sciences will be viewed separately.

Humanities universities, where the educational activity does not imply laboratory research, study social-economic processes, objective laws and subjective elements, as well as modelling of these processes with a variety of cause-effect relations.

Technical and medical universities, where the scientific activity is mainly connected with laboratory research, are aimed at elaboration and verification of new concepts, as well proving the fundamental hypotheses.

At present, taking into account the governmental conception of the country's economy innovative development, we consider fundamental research to be of utmost importance. At the same time describing new relations in the socialeconomic aspect is very significant too.

The scientific research and numerous polls of university professors revealed several different approaches to scientific activity of an educational establishment, as well as to defining the results and efficiency of this activity. We can conclude that the following indicators characterize the results and efficiency of scientific activity:

1. The number of registered research results and invention patents.

2. The number of the completed laboratory investigations.

3. The volume of financing of scientific research by the state, the educational institutions and investors.

4. The number of published scientific articles with the research results.

It should be noted that the above-mentioned criteria are to a large extent subjective, as they are greatly influenced by such factors as the university potential depending on the historical development and existing experience, the type of the university (state, private, technical, humanitarian), and the status of the respondent.

Scientific work is the droit of the teaching personnel, the non-material asset of high specificity, having its own value and obliged to benefit the right-holder as well as the persons who possess the results of intellectual activity. It should be of use for the whole society, promoting the dynamic development of economic, social-cultural relations and technical potential of the country. Thus, management of scientific activity is connected with highly specific assets. The foreign and Russian researchers-institutionalists have shown that the level of assets specificity is directly interdependent with the level of transactional costs, having an opportunistic nature (Williamson, 1985, p. 296; 1996, p. 72; Williamson \& Winter, 1993, р. 106; Крамин, 2007b; Попов \& Симонова, 2005, р. 126).

Scientific work is the result of researchers' activity. Activation of research and control over it is done through personnel motivation and overall control over its efficiency. Thus, we can consider scientific activity as interaction with particular researchers. The number and quantity of scientific research determines the volume of their intellectual capital and, correspondingly, their value for the university.

The system of scientific work motivation in educational sphere possesses special features, which is not only material awarding for the research results. In this system we can highlight "self-motivation" as a key element, as assigning of a scientific degree presupposes carrying out research during post-graduate studies, according to the rules of Higher Attestation Committee of the Russian Federation. As a result, the direct indicator of university's scientific achievements is, first of all, the number of lecturers having a scientific degree, and a number of the theses defended.

The general specialization of a university, being the main fcator of scientific activity, results from the experience in a particular field, the topicality of the research, and the correspondence between the research themes and the general state and public interests.

Business processes in science should determine intensification of all positive factors influencing the final results.

Unification of business processes in scientific activity is subject to the principle of optimism and sufficiency, i.e., the pattern presupposes beneficial conditions for carrying out this activity. It is assumed that the system is static and balanced, there is no negative influence. The factors capable of misbalancing the system include: lack of financing, shortage of human resources, bureaucratic barriers, patent legislation issues, etc. These factors exist in practice. The level of transactional costs, in this case, is calculated in a standard way - by scenario analysis and project management technique.

The main provisions of human resources policy and the system of processes are typical for all universities. The system of selecting and evaluating the human potential of a university should meet the modern requirements and 
determine the vector of personnel development not only towards increasing the lecturers' qualification, which is traditional for the Russian universities, but towards developing the key market competences of the personnel. We should abandon the traditional pattern by which only the lecturers were evaluated.

The level of the lecturers' qualification is very important, but it is not the only parameter of the personnel potential, which determines the efficiency and results of a university. Special attention should be paid to administrative workers of all levels, as it is their professional qualities that determine the adequacy of the chosen market strategy and efficiency of the tactics of achieving it.

Taking into account that transactional costs are of informational nature, the efficiency of informational streams significantly influences their level, and enables to sufficiently minimize them. The information technologies (IT) enable a university to increase the efficiency of all spheres of activity, thus the key measure is to create a reliable and efficient corporate informational environment $(\mathrm{CIE})$ of a university. $\mathrm{CIE}$ informational systems are usually created as accounting systems for inputting and systematization of corporate data. Further they can be transformed into systems for business processes automatization.

Sometimes the systems have built-in algorithms of modelling and support of decision-making process. The main condition of CIE usefulness is the coverage of the main business processes by CIE services, taking into account the data/processes integration and full availability of the services and information for all users - from students to the rector, including the external ones - employers, parents, etc. The distinctive feature of modern IT solutions is their active impact on the processes already formed at a university, and initiating of the new integrated processes.

For the effective development and maintenance of informational systems it is necessary to arrange close cooperation of technical specialists and professors who are aware of the university management issues (Chang \& Chou, 2011; Kerr, Burgess, Houghton, \& Murray, 2012). The specialists need a tool providing the input of new and changing the existing notions in $\mathrm{CIE}$, which reflect the sphere of education.

Speaking about the informational systems development, it is impossible to distinguish the complex and hierarchy of unified business processes, as they differ in each university. transactional costs, connected with the processes in the mentioned spheres of activity, should be evaluated and managed individually (Dietrich, 2008).

Thus, the work views business processes in an educational establishment as prerequisites, factors and specific features of transactional costs. The research serves as the basis for their quantitative evaluation and elaborating the techniques for their reduction.

\section{References}

Chang, H.-H., \& Chou, H.-W. (2011). Drivers and effects of enterprise resource planning post-implementation learning. Behaviour \& Information Technology, 30(2), 251-259.

Hepner, M., \& Dickson, W. (2013). The Value of ERP Curriculum Integration: Perspectives from the Research. Journal of Information Systems Education, 24(4), 309.

Joseph, G., \& George, A. (2002). ERP, learning communities, and curriculum integration. Journal of Information Systems Education, 13(1), 51-58.

Nagimova, A.M., Safiullina, F.R. (2014). Combination of university training with employment among Kazan' students. Sotsiologicheskie Issledovaniya, (4), pp. 121-124.

Kerr, D., Burgess, K. J., Houghton, L., \& Murray, P. A. (2012). Improving training in enterprise resource planning systems implementation through communities of practice. International Journal of Learning and Change, 6(3), 207-222.

Kramin, M. V., Safiullin, L. N., Kramin, T. V., \& Timiryasova, A. V. (2014). Drivers of economic growth and investment attractiveness of Russian regions. Life Science Journal, 11(6s).

Kramin, T. V., Ismagilova, G. N., \& Kramin, M. V. (2014). Assessment of Effect of Large Investment Projects on Development of Investment Potential of Regions of Russia as Exemplified by Universiade 2013 in Kazan1. Mediterranean Journal of Social Sciences, 5(18), 255.

Kramin, T. V., Safiullin, L. N., \& Timiryasova, A. V. (2014). Defining Priorities of Management of Investment Attractiveness of the Region and their Consideration in the Framework of Implementing Large Sports Events1. Mediterranean Journal of Social Sciences, 5(18), 275.

Lunenburg, F., \& Ornstein, A. (2011). Educational Administration: Concepts and Practices: Cengage Learning.

Tsertseil, J.S. The way of clusters uprising and development in the region (By the example of the petrochemical cluster in the republic of Tatarstan). Mediterranean Journal of Social Sciences, Volume 5, Issue 18 SPEC. ISSUE, 2014, Pages 125-128

Safina, D., Podgornaya, A. (2014). Mobbing as an organizational phenomenon impeding implementation of changes. Mediterranean Journal of Social Sciences, 5 (18 SPEC. ISSUE), pp. 187-192

Seng, D., \& Churilov, L. (2003). Business process-oriented information support for a higher education enterprise. PACIS 2003 Proceedings, 1055-1074. 